\title{
Notoginsenoside R1 induces DNA damage via PHF6 protein to inhibit cervical carcinoma cell proliferation
}

\author{
TING CAI ${ }^{1,2}$, WENQUAN WU ${ }^{3}$, LONGHUA GUO $^{3}$, YONGWU XIA $^{3}$, XIAOXIN JIANG ${ }^{3}$, \\ LIMEI ZHANG $^{1}$, FEIDING PENG ${ }^{1}$ and PINGHONG MING ${ }^{3}$ \\ ${ }^{1}$ Department of Acupuncture and Moxibustion, Shenzhen Second People's Hospital, The First Affiliated \\ Hospital of Shenzhen University, Shenzhen, Guangdong 518055; ${ }^{2}$ Clinical College of Chinese \\ Medicine, Hubei University of Chinese Medicine, Wuhan, Hubei $430065 ;{ }^{3}$ Department of Clinical \\ Laboratory, The People's Hospital of Longhua, Shenzhen, Guangdong 518109, P.R. China
}

Received February 20, 2020; Accepted December 18, 2020

DOI: $10.3892 / \mathrm{mmr} .2021 .11881$

\begin{abstract}
Notoginsenoside R1 (NGR1), a monomer of Traditional Chinese medicine, is from the Panax notoginsenoside complex, and has been reported to inhibit the proliferation of various types of cancer. However the mechanism underlying NGR1-mediated inhibition of cervical carcinoma cell proliferation remains unclear. Therefore, the current study aimed to investigate the antitumor effects of NGR1 on cervical carcinoma cell lines (CaSki and HeLa cells) in vitro. The Cell Counting Kit- 8 and soft agar cell colony formation assay results revealed that NGR1 suppressed the viability and the number colonies of CaSki and HeLa cells, respectively. Furthermore, the DAPI staining, flow cytometry and western blotting results revealed that NGR1 induced cervical carcinoma cell apoptosis, cell cycle arrest in the $S$ phase, upregulation of cyclin A2 and CDK2 expression levels, and downregulation of cyclin D1 expression levels. To further investigate the mechanisms of NGR1, DNA-damage-related proteins, including H2A.X variant histone (H2AX), ATR serine/threonine kinase (ATR) and p53, and the nucleolus protein, plant homeodomain finger protein 6 (PHF6) were analyzed. The results indicated that NGR1 triggered the phosphorylation of H2AX and ATR in a dose- and time-dependent manner, and downregulated the expression level of PHF6 and upregulated the expression level of p53 in a dose- and time-dependent manner. In conclusion, the findings of the present indicated that NGR1 may inhibit the viability of cervical carcinoma cells and induce cell apoptosis via DNA damage, which may be activated by the downregulation of PHF6 expression levels, and the subsequent triggering of the phosphorylation of $\mathrm{H} 2 \mathrm{AX}$ and ATR. In addition, NGR1 may
\end{abstract}

Correspondence to: Dr Pinghong Ming, Department of Clinical Laboratory, The People's Hospital of Longhua, 38 Jianshe Road, Longhua, Shenzhen, Guangdong 518109, P.R. China

E-mail:mph711@outlook.com

Key words: notoginsenoside R1, DNA damage, cell proliferation, apoptosis, plant homeodomain finger protein 6 exert an ability to arrest cervical carcinoma cells in the $S$ phase and upregulate the expression levels of cyclin A2 and CDK2. Therefore, NGR1 may serve as a novel chemotherapeutic agent for cervical carcinoma.

\section{Introduction}

Cervical cancer is the fourth most common type of malignant cancer among women worldwide, resulting in $~ 570,000$ new cases in 2018. Among the 311,000 global cervical cancer-related deaths in 2018, $90 \%$ occurred in low and middle income countries $(1,2)$. Therefore, identifying high quality and inexpensive agents to prevent and treat cervical cancer is important. Previous research has reported that the occurrence of cervical carcinoma was associated with numerous factors, including persistent human papillomavirus (HPV) infection, chromosomal telomerase activation, genetic mutations and immune system dysfunction (3-8). However, the pathogenesis of cervical carcinoma is not completely understood. Therefore, the pathogenesis of cervical carcinoma should be further investigated to improve the clinical diagnosis and efficacy of treatments.

Chemotherapy has been shown to be effective for treating cervical carcinoma, particularly suitable for the treatment of patients with terminal disease or metastatic tumors. However, chemotherapy is often accompanied by various adverse reactions, including toxicity and drug resistance $(9,10)$, which severely impacts the quality of life of surviving patients with cancer. Therefore, it remains necessary to discover anticancer drugs with high efficiency and low toxicity, which can improve patient immunity, enhance the efficacy of chemotherapy and prolong and improve the quality of life of patients.

Panax notoginsenoside, a traditional Chinese medicine, was found to serve as an antioxidant to scavenge free radicals, prevent and treat cardiovascular, central neural and cerebrovascular diseases, promote angiogenesis and immunity, decrease the levels of blood fat and blood pressure and exert tumor suppressive effects (11-17). Panax notoginsenoside has been used in combination with chemotherapy due to its ability to boost the body's innate immunity to improve the curative effect against aplastic anemia and solid tumor $(15,17)$. Notoginsenoside R1 (NGR1) is one of the major active 
constituents of Panax notoginsenoside. A previous study reported that NGR1 significantly suppressed the proliferation of colorectal cancer cells and arrested cells in the S phase (18). Moreover, NGR1 also effectively reduced the invasion and metastasis of lung cancer (19). However, few studies have investigated the role of NGR1 in cervical cancer, and the mechanism of action of NGR1 in cervical carcinoma remains to be elucidated. In a preliminary study, NGR1 was discovered to exhibit moderate toxicity, which inhibited cervical carcinoma cell viability. Therefore, the present study further investigated NGR1 and its cytotoxic mechanisms.

\section{Materials and methods}

Reagents. pEGFP-C1-plant homeodomain finger protein 6 (PHF6) was gifted by Dr DJ Picketts (Regenerative Medicine Program, Ottawa Hospital Research Institute). NGR1 (cat.no.110745) was obtained from Nanjing SenBeiJiaBiological Technology Co., Ltd.; the purity of NGR1 was $\geq 98 \%$ and the chemical structure is shown in Fig. 1A. NGR1 was dissolved in DMSO to a final concentration of $10 \mathrm{mM}$, and was stored at $-20^{\circ} \mathrm{C}$. DMEM was purchased from Hyclone; Cytiva, FBS was obtained from Gibco; Thermo Fisher Scientific, Inc., and Cell Counting Kit-8 (CCK-8), DAPI and BCA kits were purchased from Meilunbio. The Annexin V-FITC Apoptosis Detection kit was purchased from Beyotime Institute of Biotechnology. The following primary antibodies were purchased from Abcam: Anti- $\gamma \mathrm{H} 2 \mathrm{~A}$.X variant histone [H2AX; phosphorylated (p) on serine 139] (cat. no. ab81299), anti-H2AX (cat. no. ab229914), anti-Bcl-2 (cat. no. ab182858), anti-ATR serine/threonine (ATR) (cat. no. ab184137), anti-p-ATR (S428) (cat. no. ab178407), anti-PHF6 (cat.no. ab173304), anti-cyclin A2 (cat.no. ab181591), anti-cyclin D1 (cat. no. ab16663), anti-CDK2 (cat. no. ab32147), anti-p53 (cat. no. ab179477), anti-PARP1 (cat. no. ab191217), anti-nucleolin (cat. no. ab22758) and anti-GAPDH (cat. no. ab181602). Anti-Lamin B1 (cat. no. 13435) and anti-cleaved caspase-3 (cat. no. 9661) were purchased from Cell Signaling Technology. DMSO, SDS and Triton ${ }^{\text {TM }}$ X-100 were purchased from Sigma-Aldrich; Merck KGaA. Goat anti-rabbit IgG H\&L (DyLight ${ }^{\circledR} 488$ ) secondary antibody (cat. no. ab96899) was obtained from Abcam. HRP-conjugated anti-rabbit IgG secondary antibody (cat. no. sc-2357) and PE-conjugated anti-rabbit IgG secondary antibody (cat. no. sc-3753) were obtained from Santa Cruz Biotechnology, Inc. Small interfering RNA (siRNA/si) targeting PHF6 (siPHF6) and negative control siRNA were purchased from Guangzhou RiboBio Co., Ltd. NE-PER Nuclear and Cytoplasmic Extraction reagents (cat. no. 78835), Opti-MEM (cat. no. 11058021) and Lipofectamine ${ }^{\circledR} 2000$ transfection reagent (cat. no. 11668500) were purchased from Thermo Fisher Scientific, Inc.

Cell culture. HeLa and CaSki cells were purchased from the American Type Culture Collection. Cells were cultured in DMEM supplemented with $10 \%$ FBS and $1 \%$ penicillin $(100 \mathrm{U} / \mathrm{ml})$ and $1 \%$ streptomycin $(100 \mu \mathrm{g} / \mathrm{ml})$. Cells were maintained in a suitable environment at $37^{\circ} \mathrm{C}$, with an atmosphere containing $5 \%(\mathrm{v} / \mathrm{v}) \mathrm{CO}_{2}$.

CCK- 8 assay. Cell viability of HeLa and CaSki cells was determined using a CCK-8 assay. Briefly, 5x10 4 HeLa and
CaSki cells/well were cultured in 96 -well plates at $37^{\circ} \mathrm{C}$ for $12 \mathrm{~h}$. Subsequently, cells were treated with different concentrations of NGR1 $(0,0.1,0.2,0.4,0.8,1.6 \mathrm{mM})$ at $37^{\circ} \mathrm{C}$ for 24 and $48 \mathrm{~h}$. Alternatively, cells were treated for $24 \mathrm{~h}$ with: i) siPHF6; ii) siPHF6 + 0.4 mM NGR1; iii) PHF6; iv) PHF6 + 0.4 mM NGR1; or v) 0 mM NGR1 (control group). Following the incubation, cells were washed twice with PBS and $100 \mu \mathrm{l}$ DMEM supplemented with $10 \%$ CCK- 8 reagent was added to each well and incubated at $37^{\circ} \mathrm{C}$ for $2 \mathrm{~h}$. The absorbance was measured at a wavelength of $460 \mathrm{~nm}$ on an Epoch $^{\text {TM }} 2$ microplate reader (BioTek Instruments, Inc.). The cell viability rate was calculated according to the following formula: $[(\mathrm{As}-\mathrm{Ab}) /(\mathrm{Ac}-\mathrm{Ab})] \mathrm{x} 100 \%$, where As represents the absorbance of the NGR1 treatment groups, Ac represents the absorbance of the control group and $\mathrm{Ab}$ represents the absorbance of material background. The half maximal inhibitory concentration $\left(\mathrm{IC}_{50}\right)$ of NGR1 in the HeLa and CaSki cell lines was calculated using Origin Pro 8 software (OriginLab).

Soft agar cell colony formation assay. The cell colony forming assay was performed as previously described (20). Briefly, basal agarose was prepared with 1X DMEM, 0.6\% low-melting-point agarose (Amresco, LLC), 10\% FBS, $1 \%$ penicillin and $1 \%$ streptomycin. The basal agarose contained $0.2,0.4$ or $0.8 \mathrm{mM}$ NGR1. The basal agarose compounds were poured into a 6 -well plate. The top agarose layer was prepared with 1X DMEM, 0.3\% low-melting-point agarose, $10 \%$ FBS, $1 \%$ penicillin and $1 \%$ streptomycin. Subsequently, cells $\left(1 \times 10^{3}\right.$ cells/well) were added to make the top agarose. The top agarose also contained $0.2,0.4$ or $0.8 \mathrm{mM}$ NGR1. The top agarose compounds were poured onto the basal agarose. Cells were incubated at $37^{\circ} \mathrm{C}$ for 12 days. Subsequently, cell colonies were fixed with $4 \%$ paraformaldehyde for $20 \mathrm{~min}$ at room temperature, and stained with $0.5 \%$ crystal violet for $15 \mathrm{~min}$ at room temperature. Data were analyzed using ImageJ software (version 1.8.0; National Institutes of Health).

DAPI staining. HeLa cells $\left(1 \times 10^{5}\right.$ cells/well) were seeded into a 6-well culture plate and treated with $0,0.2,0.4$ or $0.8 \mathrm{mM}$ $\mathrm{NGR} 1$ for $24 \mathrm{~h}$ at $37^{\circ} \mathrm{C}$. Cells were fixed with $4 \%$ formaldehyde for $20 \mathrm{~min}$ at room temperature. Nuclei were stained with $4 \mu \mathrm{g} / \mathrm{ml}$ DAPI for $20 \mathrm{~min}$ at room temperature and washed with PBS. Cell nuclear morphology was visualized using a BX43 fluorescence microscope (Olympus Corporation).

Flow cytometric analysis of apoptosis. Cells ( $1 \times 10^{5}$ cells/well) were cultured in 6-well plates until reaching $90 \%$ confluence, and were then treated with $0,0.2,0.4$ or $0.8 \mathrm{mMNGR} 1$ for $12 \mathrm{~h}$ at $37^{\circ} \mathrm{C}$. Apoptosis was subsequently evaluated using the Annexin V-FITC Apoptosis Detection kit according to the manufacturer's protocol. Briefly, $1 \times 10^{6}$ cells were collected, centrifuged at $1,000 \mathrm{x} \mathrm{g}$ for 5 min at room temperature, washed with PBS and resuspended in $195 \mu \mathrm{l}$ Annexin V-FITC binding buffer. Subsequently, cells were stained with $5 \mu \mathrm{l}$ Annexin V-FITC and $10 \mu \mathrm{l}$ PI solution at room temperature in the dark for $15 \mathrm{~min}$. Cells were filtered with a 300-mesh nylon film and maintained on ice until analysis using an Accuri C6 flow cytometer (BD Biosciences). Early and late apoptosis was analyzed using FlowJo software (version 7.6; FlowJo, LLC). All experiments were performed independently and repeated three times. 
Cell cycle analysis. Following the treatment of cells with NGR1, the cell cycle distribution was analyzed via flow cytometry. Briefly, cells were treated with $0,0.2,0.4$ or $0.8 \mathrm{mM}$ NGR1 for $24 \mathrm{~h}$ at $37^{\circ} \mathrm{C}$. Subsequently, $1 \times 10^{6}$ cells were collected, centrifuged at $1,000 \mathrm{x} \mathrm{g}$ for $5 \mathrm{~min}$ at $4^{\circ} \mathrm{C}$, washed with cold PBS and fixed with precooled $70 \%$ ethanol at $4^{\circ} \mathrm{C}$ for overnight. After washing, cells were resuspended in $0.535 \mathrm{ml}$ dye buffer, which contained $10 \mu \mathrm{l}$ RNase (50X) and $25 \mu \mathrm{l}$ PI (25X), and incubated in the dark at room temperature for $30 \mathrm{~min}$. Cells were filtered with a 300-mesh nylon film, and analyzed using an Accuri C6 flow cytometer (BD Biosciences) and ModFit LT software (version 3.2; Verity Software House).

Cell transfection. HeLa cells $\left(1 \times 10^{5}\right.$ cells/well) were seeded into 6 -well plates and cultured to $80 \%$ confluence. Lipofectamine ${ }^{\circledR} 2000(5 \mu \mathrm{l})$ was used to transfect the cells with specific small interfering RNA (siRNA/si) targeting PHF6 (siPHF6; $20 \mathrm{nM}$ ), pEGFP-C1 empty plasmid (1 $\mu \mathrm{g})$, pEGFP-C1 plasmid overexpressing PHF6 (pEGFP-C1-PHF6; $1 \mu \mathrm{g}$ ) or the non-specific control siRNA [negative control (NC); $20 \mathrm{nM}$ ]. siRNAs or plasmids were mixed with Lipofectamine ${ }^{\circledR} 2000$ in Opti-MEM culture medium at room temperature for $20 \mathrm{~min}$. Subsequently, the mixtures were added to each well for $6 \mathrm{~h}$ at $37^{\circ} \mathrm{C}$. After $6 \mathrm{~h}$, the mixtures were removed and replaced with complete medium (1X DMEM supplemented with 10\% FBS and $1 \mathrm{X}$ antibiotics) to culture for $24 \mathrm{~h}$ at $37^{\circ} \mathrm{C}$. siPHF6s and siRNA NC were obtained from Guangzhou RiboBio Co., Ltd. and the sequences were as follows: siPHF6-1, 5'-GGACAG TTACTAATATCTG-3'; siPHF6-2, 5'-GCACGAAGCTGA TGTGTTC-3'; siPHF6-3, 5'-CCACTGTGCATTGCATGA T-3-'; and NC, 5'-UUCUCCGAACGUGUCACGU-3'.

Immunofluorescence staining. Immunofluorescence staining was performed as previously described (20). Briefly, cells were fixed with $4 \%$ paraformaldehyde for $20 \mathrm{~min}$ at room temperature and slides were subsequently incubated with $0.1 \%$ Triton $\mathrm{X}-100$ for $5 \mathrm{~min}$ at room temperature. Cells were then incubated at $4^{\circ} \mathrm{C}$ overnight with anti-PHF6 (1:100), anti-nucleolin (1:100) and anti- $\gamma \mathrm{H} 2 \mathrm{AX}(1: 100)$ primary antibodies. Following the incubation, the cells were washed and further incubated with a fluorescein-labeled secondary antibody (1:100) for $1 \mathrm{~h}$ at room temperature. The cell nucleus was subsequently stained with DAPI $(4 \mu \mathrm{g} / \mathrm{ml})$ for $30 \mathrm{~min}$ at room temperature. Stained cells were observed under a confocal laser scanning microscope (Olympus Corporation).

Western blotting. Western blotting was performed as previously described (20). Briefly, cytoplasmic and nuclear protein extraction (H2AX, $\gamma \mathrm{H} 2 \mathrm{AX}$, Lamin B1 and PHF6) were performed using the NE-PER ${ }^{\mathrm{TM}}$ Nuclear and Cytoplasmic Extraction kit (Thermo Fisher Scientific, Inc.) and other total proteins were extracted from cells using RIPA lysis buffer (Thermo Fisher Scientific, Inc.). Total protein concentrations were quantified using a BCA kit (Beyotime Institute of Biotechnology). Equal amounts of cell lysate (40 $\mu \mathrm{g} / \mathrm{lane})$ were separated by $10 \%$ SDS-PAGE, transferred onto a PVDF membrane and blocked with 5\% skim milk solution at room temperature for $1 \mathrm{~h}$. Then, after washing with PBS, the PVDF membranes were incubated with the following primary antibodies (all 1:1,000 except anti-GAPDH) overnight at $4^{\circ} \mathrm{C}$ : Anti-cleaved caspase-3, anti-poly (ADP-ribose) polymerase 1 (PARP1), anti-Bcl-2, anti-cyclin D1, anti-CDK2, anti-cyclin A2, anti-ATR, anti-p-ATR, anti-p53, anti-H2AX, anti- $\gamma \mathrm{H} 2 \mathrm{AX}$, anti-Lamin B1, anti-PHF6 and anti-GAPDH $(1: 5,000)$. Following the primary antibody incubation at $4^{\circ} \mathrm{C}$ for overnight, the membranes were washed with PBS and incubated with an IgG HRP-conjugated secondary antibody $(1: 5,000)$ at room temperature for $1 \mathrm{~h}$. Protein bands were visualized using an ECL detection kit (Thermo Fisher Scientific, Inc.). Densitometric analysis was performed using ImageJ software (version 1.8.0; National Institutes of Health).

Cytoplasmic and nuclear protein extraction. HeLa cells were cultured in a $10-\mathrm{cm}$ culture dish $\left(\sim 5 \times 10^{6}\right.$ cells/well $)$. Cytoplasmic and nuclear protein extraction were performed using the NE-PER ${ }^{\mathrm{TM}}$ Nuclear and Cytoplasmic Extraction Kit (Thermo Fisher Scientific, Inc.). Briefly, the cells were collected and washed with pre-cooled PBS and resuspended in $200 \mu \mathrm{l}$ CER I supplemented with PMSF, protease and phosphatase inhibitors (Halt ${ }^{\mathrm{TM}}$ Protease and Phosphatase Inhibitor Cocktail; Thermo Fisher Scientific, Inc.). Cells were incubated on ice for $10 \mathrm{~min}$, then $11 \mu \mathrm{l}$ ice-cold CER II was added to the cell suspension and centrifuged at $16,000 \mathrm{x}$ g for $5 \mathrm{~min}$ at $4^{\circ} \mathrm{C}$. The supernatant containing the cytoplasmic extract was immediately transferred to a new pre-chilled tube and stored at $-80^{\circ} \mathrm{C}$. The precipitate containing the nuclear component was suspended in $100 \mu \mathrm{l}$ ice-cold NER with protease inhibitors and the suspension was oscillated in the tube for $15 \mathrm{sec}$ every $10 \mathrm{~min}$ for a total of $40 \mathrm{~min}$. Subsequently, the suspension was centrifuged at $16,000 \mathrm{x} \mathrm{g}$ for $10 \mathrm{~min}$ at $4^{\circ} \mathrm{C}$ The obtained supernatant contained the nuclear component, which was immediately transferred to a new pre-chilled tube and stored at $-80^{\circ} \mathrm{C}$.

Statistical analysis. All experimental protocols were repeated at least three times. Statistical analyses were performed using Origin Pro 8 software (OriginLab). Experimental data are presented as the mean \pm SD. Statistical differences between groups were determined using a one-way ANOVA followed by a Tukey's post hoc test. $\mathrm{P}<0.05$ was considered to indicate a statistically significant difference.

\section{Results}

NGR1 inhibits the proliferation of cervical carcinoma cells. It was first determined whether NGR1 could inhibit the proliferation of the cervical carcinoma cell lines, HeLa and CaSki were treated with NGR1 $(0,0.10 .2,0.4,0.8,1.6 \mathrm{mM})$ for 24 and $48 \mathrm{~h}$. The chemical structure of NGR1 is presented in Fig. 1A. Cell viability was evaluated by performing the CCK-8 assay. As shown in Fig. 1B, NGR1 exhibited moderate cytotoxicity towards inhibiting HeLa cell viability, with an $\mathrm{IC}_{50}$ of $0.8 \mathrm{mM}$ at $24 \mathrm{~h}$ and an $\mathrm{IC}_{50}$ of $0.41 \mathrm{mM}$ at $48 \mathrm{~h}$ However, the CaSki cells were more sensitive to NGR1, with an $\mathrm{IC}_{50}$ of $0.4 \mathrm{mM}$ at $24 \mathrm{~h}$ and an $\mathrm{IC}_{50}$ of $0.19 \mathrm{mM}$ at $48 \mathrm{~h}$ (Fig. 1C). The results suggested that NGR1 inhibited HeLa and CaSki cell viability in a time- and dose-dependent manner. The exact $\mathrm{IC}_{50}$ of NGR1 in cervical carcinoma cell lines is presented in Table I.

Soft agar cell colony formation experiments are often used to evaluate the proliferation of malignant cancer cells (20). Subsequently, the effect of NGR1 on CaSki cell colony formation 

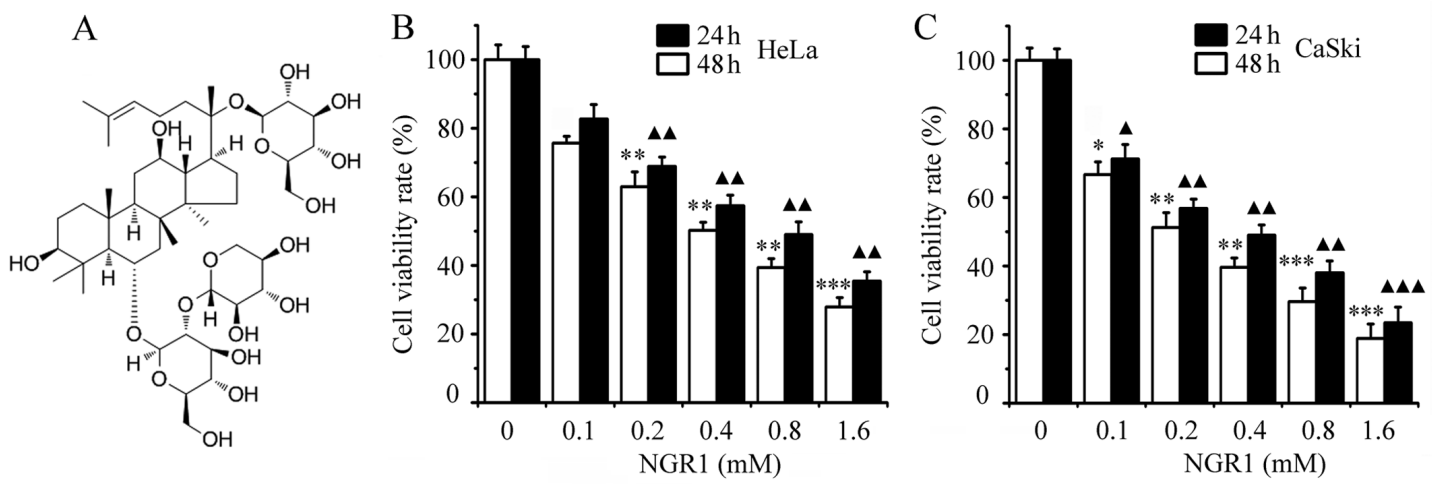

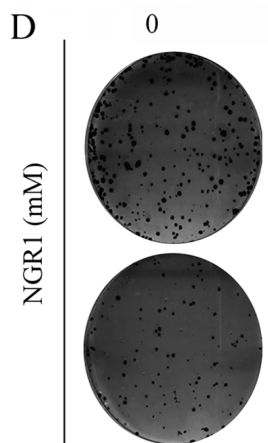

0.4

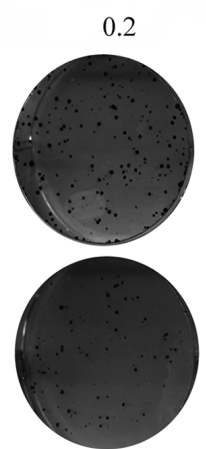

0.8

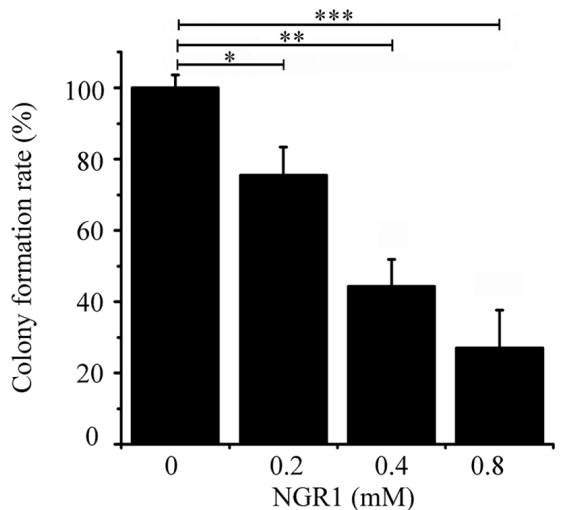

Figure 1. Inhibitory effects of NGR1 on cervical carcinoma cells. (A) Chemical structure of NGR1. Inhibitory effects of NGR1 treatment at the indicated concentrations for 24 and $48 \mathrm{~h}$ in (B) HeLa and (C) CaSki cells was determined using a Cell Counting Kit- 8 assay. ${ }^{*} \mathrm{P}<0.05,{ }^{* *} \mathrm{P}<0.01,{ }^{* * *} \mathrm{P}<0.001 \mathrm{vs} .0 \mathrm{mM}$ $24 \mathrm{~h} ;{ }^{\wedge} \mathrm{P}<0.05,{ }^{\wedge} \mathrm{P}<0.01,{ }^{\wedge \Delta} \mathrm{P}<0.001$ vs. $0 \mathrm{mM} 48 \mathrm{~h}$. (D) Soft agar colony formation assays were used to determine the colony forming ability of CaSki cells treated with NGR1 at the indicated concentrations. The colony formation rate was calculated using ImageJ software. ${ }^{*} \mathrm{P}<0.05,{ }^{* * *} \mathrm{P}<0.01,{ }^{* * * *} \mathrm{P}<0.001 . \mathrm{All}$ data are expressed as the mean \pm SD of three independent experiments. NGR1, Notoginsenoside R1.

was investigated. The present results revealed that NGR1 also significantly inhibited the colony forming ability of CaSki cells in a dose-dependent manner compared with the control cells. The number of CaSki cell colonies was significantly decreased by $0.2 \mathrm{mM}$ NGR1 compared with the control group (Fig. 1D).

NGR1 induces the apoptosis of cervical carcinoma cells. To examine whether NGR1 altered cervical cancer cell apoptosis, HeLa cells were treated with NGR1 $(0,0.2,0.4$ and $0.8 \mathrm{mM})$ for $24 \mathrm{~h}$. Cell morphological apoptosis were evaluated by DAPI staining and cell apoptotic rates were evaluated via flow cytometry. As shown in Fig. 2A, the cell nuclei exhibited irreversible condensation, and some typical apoptotic bodies were observed in the nuclei following $0.8 \mathrm{mM}$ NGR1. However, in the control group $(0 \mathrm{mM})$, the morphology of the cell nuclei was oval and regular, with homogenous color distribution. As shown in Fig. 2B, the cell apoptotic rate increased in a dose-dependent manner; compared with the control group (2.64\%), treatment with $0.2,0.4$ and $0.8 \mathrm{mM} \mathrm{NGR} 1$ increased the apoptotic rate to $5.55,12.22$ and $18.11 \%$, respectively (Fig. 2B).

Cleaved caspase- 3 is the activated form of caspase-3, which is an important marker of apoptosis (21). Therefore, the expression levels of the active form of caspase-3 following NGR1 treatment in HeLa cells for $24 \mathrm{~h}$ were investigated. The active form of caspase-3 was significantly upregulated by 0.4 and $0.8 \mathrm{mM}$ NGR1, compared with the control group (Fig. 2C). PARP1 has been discovered to serve a crucial role in DNA repair and apoptosis $(22,23)$. Therfore, the effect of
Table I. $\mathrm{IC}_{50}$ of Notoginsenoside R1 in cervical carcinoma cells.

\begin{tabular}{lcc}
\hline Cell line & $\mathrm{IC}_{50}$ at $24 \mathrm{~h}(\mathrm{mM})$ & $\mathrm{IC}_{50}$ at $48 \mathrm{~h}(\mathrm{mM})$ \\
\hline HeLa & $0.809 \pm 0.037$ & $0.400 \pm 0.023$ \\
CaSki & $0.413 \pm 0.032$ & $0.194 \pm 0.041$
\end{tabular}

$\mathrm{IC}_{50}$, half-maximal inhibitory concentration.

NGR1 on the expression of PARP1 was also assessed. The expression levels of PARP1 were also significantly upregulated by 0.4 and $0.8 \mathrm{mM}$ NGR1, compared with the control group. Conversely, the expression levels of Bcl-2, which is an oncogene that inhibits apoptosis (24), were significantly downregulated by 0.4 and $0.8 \mathrm{mM}$ NGR 1 compared with the control group (Fig. 2C).

NGR1 arrests cervical carcinoma cells in the $S$ phase of the cell cycle and activates cyclin A2 and CDK2. The aforementioned results demonstrated that NGR1 inhibited HeLa and CaSki cell viability. Therefore, whether NGR1 was able to inhibit cell viability by regulating the cell cycle was investigated. HeLa cells were treated with $0,0.2,0.4$ and $0.8 \mathrm{mM}$ NGR1 for $24 \mathrm{~h}$. Compared with the control group (0 mM; $\mathrm{S}$ phase, 25.90\%), treatment with 0.2, 0.4 and 0.8 mM NGR1 increased the $\mathrm{S}$ phase proportion to $34.13,44.32,58.63 \%$, 


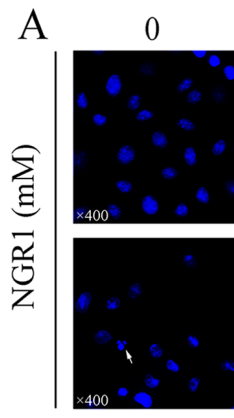

0.4

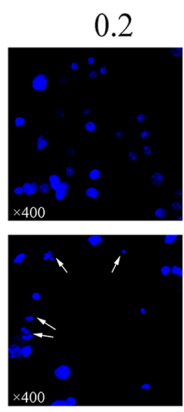

0.8

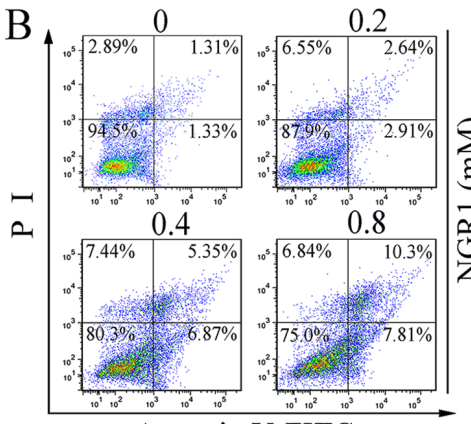

Annexin V-FITC
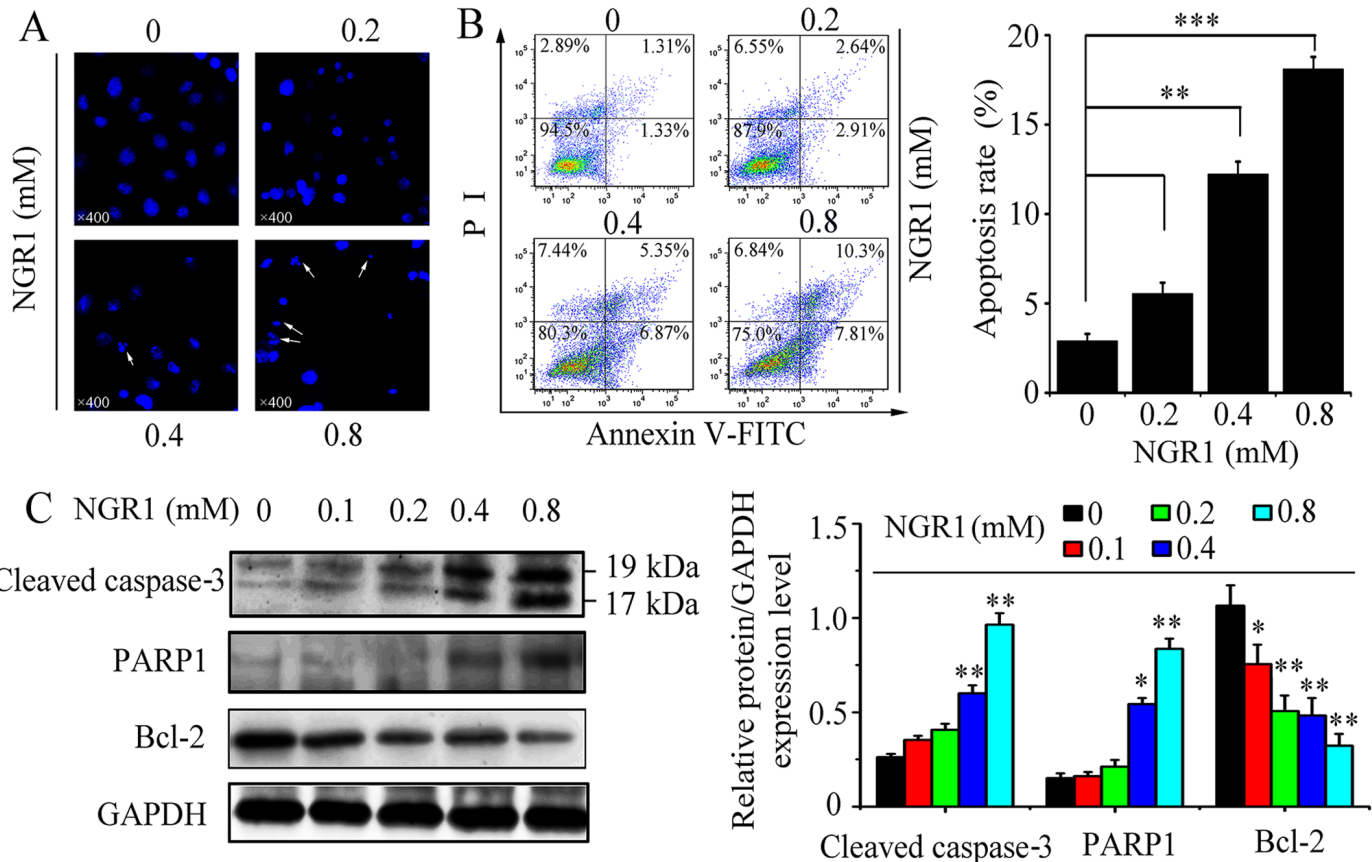

Figure 2. NGR1 induces the apoptosis of cervical cancer cells. (A) HeLa cells were treated with NGR1 at the indicated concentrations for $24 \mathrm{~h}$ and then stained with DAPI. Nuclear morphologies were observed under a fluorescence microscope. Magnification, x400. (B) Following the treatment with different concentrations of NGR1, cells were stained with Annexin V-FITC and PI and the apoptotic rates were analyzed using flow cytometry. (C) Following NGR1 treatment of HeLa cells, the expression levels of cleaved caspase-3, PARP1 and Bcl-2 were analyzed using western blotting. The relative protein expression levels were normalized to GAPDH. Data are expressed as the mean $\pm \mathrm{SD}$ of three independent experiments. ${ }^{*} \mathrm{P}<0.05,{ }^{* *} \mathrm{P}<0.01,{ }^{* * *} \mathrm{P}<0.001$ vs. 0 mM. NGR1, Notoginsenoside R1; PI, propidium iodide.
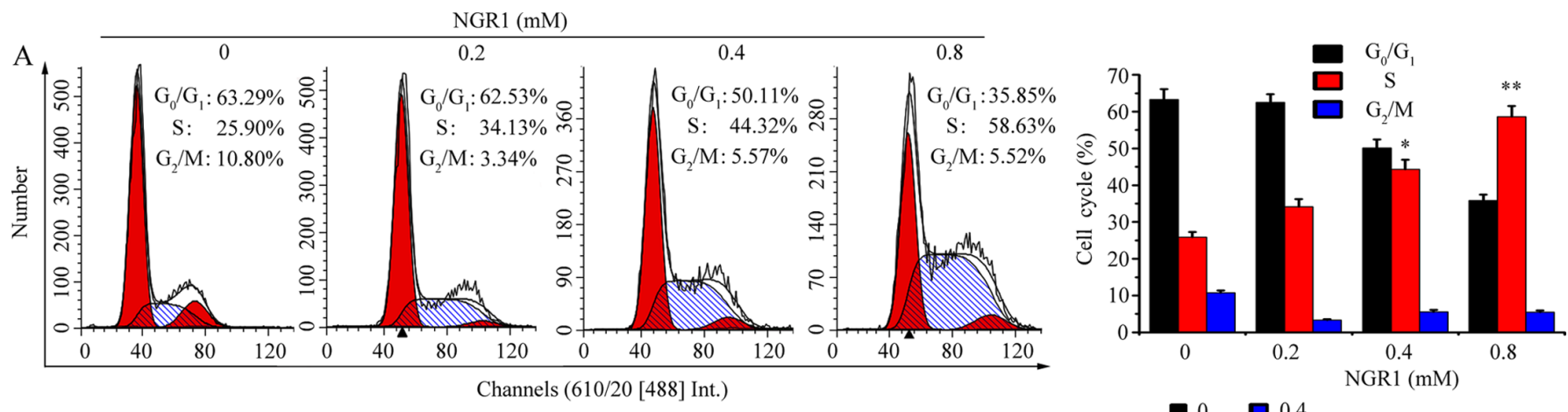

B
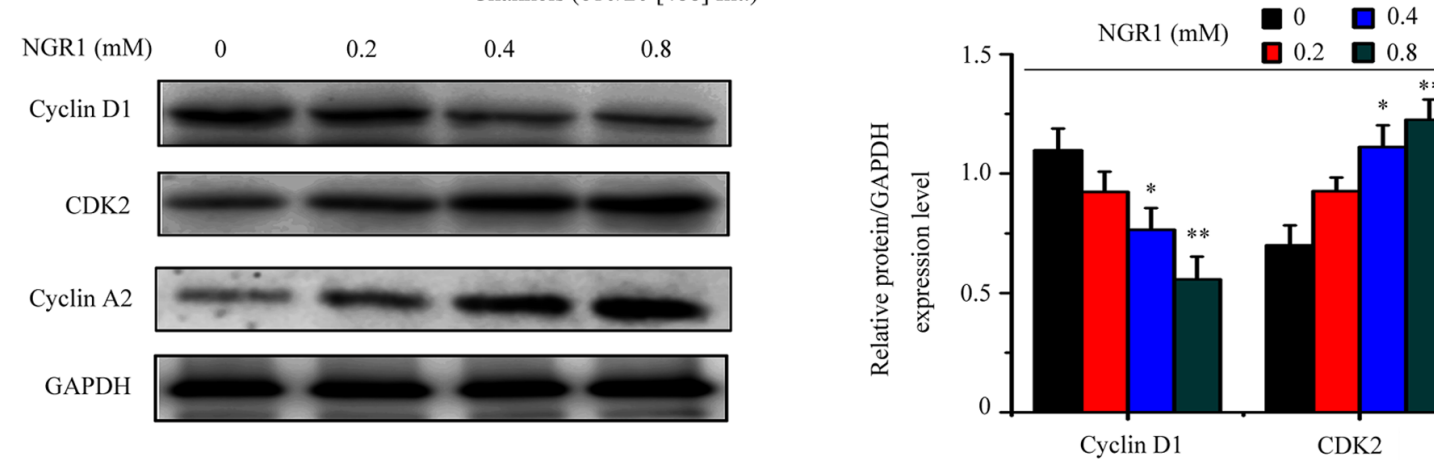

Figure 3. Effects of NGR1 treatment on the cell cycle. (A) Analysis of the cell cycle distribution of HeLa cells following the treatment with different concentrations of NGR1 (0, 0.2, 0.4 or $0.8 \mathrm{mM}$ ) were analyzed using flow cytometry. (B) Expression levels of cell cycle-associated proteins were analyzed using western blotting following the treatment with the indicated concentrations of NGR1 for $24 \mathrm{~h}$. The relative protein expression levels were normalized to GAPDH. Data are expressed as the mean $\pm \mathrm{SD}$ of three independent experiments. ${ }^{*} \mathrm{P}<0.05,{ }^{* *} \mathrm{P}<0.01$ vs. 0 mM. NGR1, Notoginsenoside R1.

respectively (Fig. 3A). Furthermore, the expression levels of cell cycle-related proteins were analyzed using western blotting. The expression levels of cyclin A2 and CDK2 were significantly upregulated by 0.4 and $0.8 \mathrm{mM} \mathrm{NGR} 1$, compared with the control group (Fig. 3B). However, the expression levels of cyclin D1, a protein involved in the $G_{0} / G_{1}$ phase of 

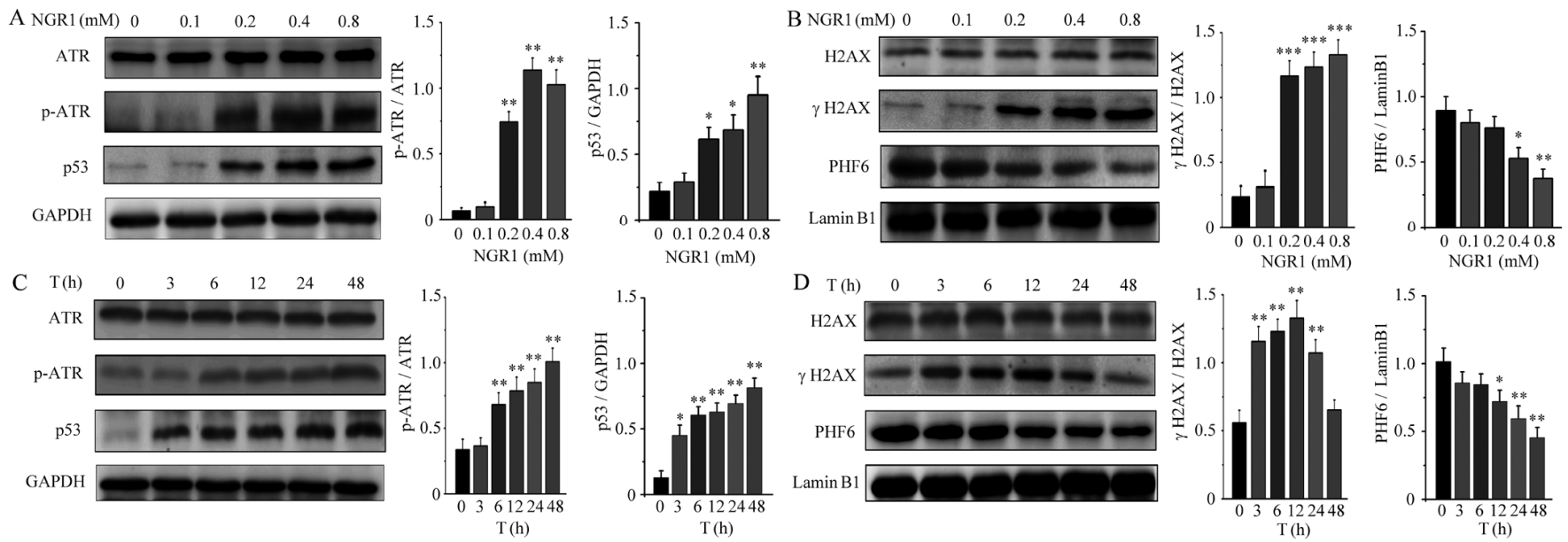

Figure 4. Effects of NGR1 on the expression levels of DNA damage-related proteins. HeLa cells were treated with a series of concentrations of NGR1 $(0,0.1,0.2,0.4$ or $0.8 \mathrm{mM})$ for $12 \mathrm{~h}$ and the expression levels of (A) ATR, p-ATR and p53 and (B) $\gamma \mathrm{H} 2 \mathrm{AX}, \mathrm{H} 2 \mathrm{AX}$ and PHF6 were analyzed using western blotting. HeLa cells were treated for different durations $(0,3,6,12,24$ or $48 \mathrm{~h})$ with $0.4 \mathrm{mM} \mathrm{NGR} 1$, and western blotting was used to analyze the expression levels of (C) ATR, p-ATR and 53 and (D) $\gamma \mathrm{H} 2 \mathrm{AX}, \mathrm{H} 2 \mathrm{AX}$ and PHF6. Data are expressed as the mean $\pm \mathrm{SD}$ of three independent experiments. ${ }^{*} \mathrm{P}<0.05,{ }^{* * *} \mathrm{P}<0.01,{ }^{* * *} \mathrm{P}<0.001 \mathrm{vs} .0 \mathrm{mM}$. NGR1, Notoginsenoside R1; ATR, ATR serine/threonine kinase; p-, phosphorylated; H2AX, H2A.X variant histone; PHF6, plant homeodomain finger protein 6.

A
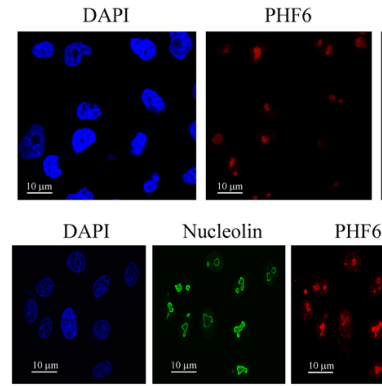

Nucleolin

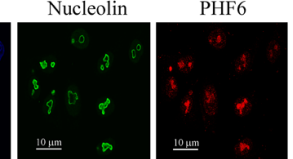

$\mathrm{C}$
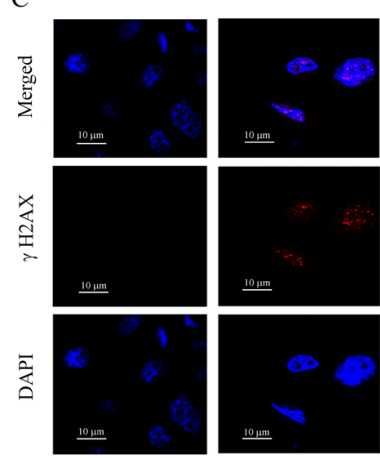

(3)
Merged

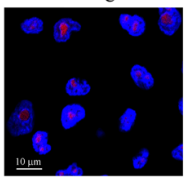

Merged
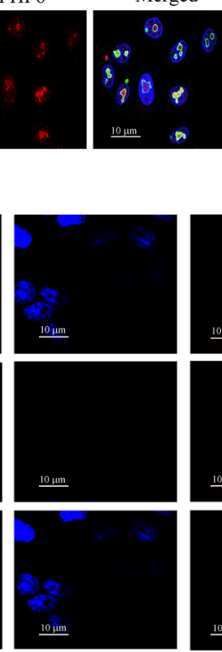

20

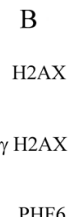

PHF6

Lamin B

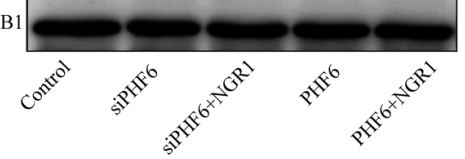

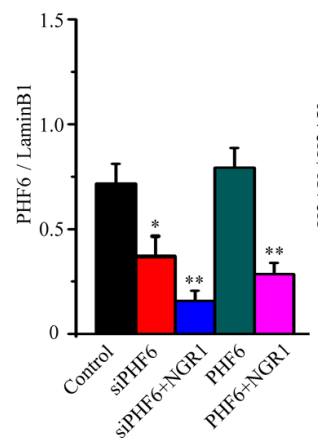

$\mathrm{D}$
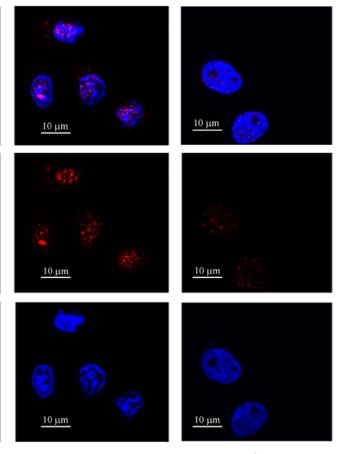

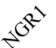
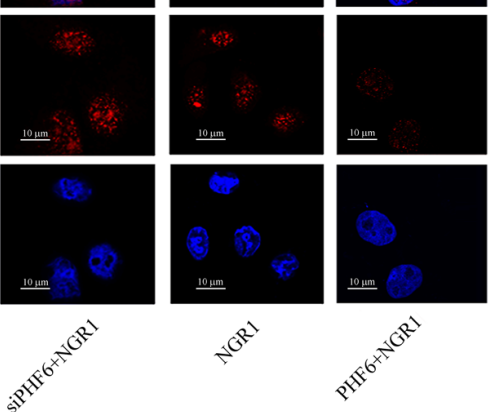
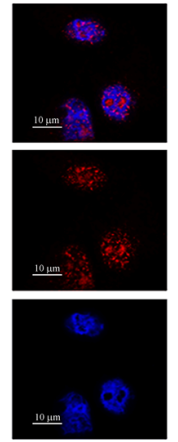

क्ष
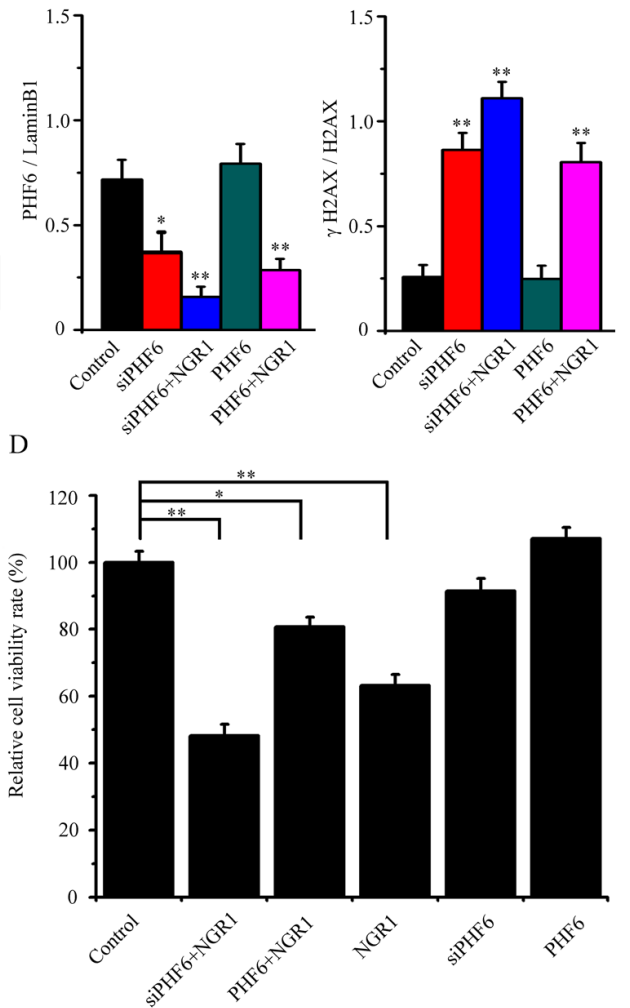

Figure 5. NGR1 induces DNA damage by inhibiting nucleolus PHF6. (A) PHF6 was discovered to be localized in the cell nucleus and nucleolus. (B) $\gamma \mathrm{H} 2 \mathrm{AX}$, H2AX and PHF6 expression levels were analyzed using western blotting following cell transfection with siPHF6 or PHF6 overexpression plasmid in the presence or absence of $0.4 \mathrm{mM}$ NGR1 treatment for $24 \mathrm{~h}$. (C) HeLa cells were transfected with siPHF6 or PHF6 overexpression plasmid treated with or without $0.4 \mathrm{mM}$ NGR1 for $12 \mathrm{~h}$, and the location of $\gamma \mathrm{H} 2 \mathrm{AX}$ foci was observed using a laser confocal microscope. (D) HeLa cells were transfected with siPHF6 or PHF6 overexpression plasmid treated with or without $0.4 \mathrm{mM}$ NGR1 for $24 \mathrm{~h}$, and the relative cell viability rates were analyzed using a Cell Counting Kit- 8 assay. Data are expressed as the mean $\pm \mathrm{SD}$ of three independent experiments. ${ }^{*} \mathrm{P}<0.05,{ }^{* *} \mathrm{P}<0.01$ vs. control (plasmid vector). NGR1, Notoginsenoside R1; PHF6, plant homeodomain finger protein 6; H2AX, H2A.X variant histone; si, small interfering RNA.

the cell cycle, were significantly decreased by 0.4 and $0.8 \mathrm{mM}$ NGR1 compared with the control group (Fig. 3B).

NGR1 upregulates the expression levels of the DNA damage regulatory proteins, $\gamma H 2 A X$ and ATR and downregulates
PHF6 expression levels. Following treatment with NGR1, the expression levels of DNA damage regulatory proteins in $\mathrm{HeLa}$ cells were measured. HeLa cells were treated with NGR1 $(0,0.1,0.2,0.4$ and $0.8 \mathrm{mM})$ for $24 \mathrm{~h}$. As shown in Fig. 4A and B, NGR1 induced H2AX and ATR phosphorylation and significantly 
upregulated the expression levels of p53 in a dose-dependent manner, In addition, NGR1 downregulated the expression levels of PHF6 in a dose-dependent manner. Compared with the control group, NGR1 significantly increased the expression levels of $\mathrm{H} 2 \mathrm{AX}$ and ATR phosphorylation and upregulated the levels of p53 at $0.2 \mathrm{mM}$, but significantly downregulated PHF6 expression levels at $0.4 \mathrm{mM}$. To assess alterations in DNA damage regulatory proteins after NGR1 treatment, HeLa cells were treated with $0.4 \mathrm{mM}$ NGR1 for $0,3,6,12,24$ or $48 \mathrm{~h}$. As shown in Fig. 4C and D, NGR1 increased H2AX and ATR phosphorylation, upregulated the expression levels of p53 and downregulated the expression levels of PHF6 in a time-dependent manner. However, compared with the control group, H2AX phosphorylation was significantly increased by NGR1 until $24 \mathrm{~h}$, returning to normal levels at $48 \mathrm{~h}$, which might be associated with NGR1 inducing excessive HeLa cell death.

NGR1 induces DNA damage to inhibit cell viability via the downregulation of PHF6 expression in the nucleolus. PHF6 is a nucleolus protein involved in numerous important biological processes, such as transcriptional regulation and chromatin remodeling (25-27). To demonstrate the localization of PHF6 in the nucleus, an immunofluorescence assay was conducted. The results of the immunofluorescence assay demonstrated that PHF6 was localized in the cell nucleus. Furthermore, the results revealed that PHF6 was specifically localized in the nucleoli (Fig. 5A). Prior to the cell transfection assay, the interference efficiencies of the siPHF6s transfection were presented in Fig. S1. Meanwhile, the transfection efficiencies of pEGFP-C1-PHF6 and siPHF6 were presented in Fig. S2. As shown in Fig. 5B, PHF6 overexpression did not alter the expression levels of $\gamma \mathrm{H} 2 \mathrm{AX}$ compared with the control group. but NGR1 treatment (PHF6 + 0.4 mM NGR1) significantly increased $\gamma \mathrm{H} 2 \mathrm{AX}$ expression levels compared with the control group (Fig. 5B). Therefore, the results suggested that PHF6 overexpression did not alter DNA damage. However, following transfection with siPHF6, the expression level of the $\gamma \mathrm{H} 2 \mathrm{AX}$ protein was significantly upregulated compared with the control group. The addition of NGR1 (siPHF6 + 0.4 mM NGR1 group) to si-PHF6-transfected HeLa cells markedly increased $\gamma \mathrm{H} 2 \mathrm{AX}$ protein expression levels compared with the siPHF6 group. Thus, the results suggested that PHF6 knockdown damaged DNA, but also cooperated with NGR1 to induce DNA damage (Fig. 5B). The aforementioned results were further supported by the immunocytochemistry results, which indicated that the number of $\gamma \mathrm{H} 2 \mathrm{AX}$ foci was not markedly difference between the PHF6 and control groups. However, the number of $\gamma \mathrm{H} 2 \mathrm{AX}$ foci was markedly increased in the PHF6 + NGR1, NGR1 and siPHF6 + NGR1 groups compared with the control group, especially in siPHF6 + NGR1 group (Fig. 5C). The results indicated that NGR1 might induce DNA damage via downregulating PHF6 expression. Furthermore, the association between PHF6, NGR1 and cell viability was also investigated.PHF6 overexpression did not alter HeLa cell viability compared with the control group. However, PHF6 knockdown slightly inhibited HeLa cell viability compared with the control group, although this was not significant. In all the experimental groups, the siPHF6 + NGR1 group displayed the most obvious significant inhibitory effect on cell viability compared with the control group. The results revealed that siPHF6 promoted NGR1-induced inhibition of cell viability (Fig. 5D).

\section{Discussion}

NGR1 has been extracted from the Panax notoginsenoside complex and is used as a valuable Chinese herbal medicine due to its reported multiple beneficial effects on human health, such as inhibiting inflammatory responses, antimyocardial ischemia and hypoxia, antiatherosclerosis, antiplatelet aggregation effects (28-32). Several previous studies have reported that NGR1 exerted antihepatoma effects and inhibited human colorectal cancer metastasis $(33,34)$; however, few have reported the role of NGR1 in cervical carcinoma. The present study demonstrated that NGR1 had moderate antitumor activity and inhibited the viability of cervical carcinoma cells in a time- and dose-dependent manner. In addition, NGR1, as a immunologic adjuvant to enhance immunity $(35,36)$, may serve as a beneficial candidate for chemotherapy to treat cervical carcinoma.

Apoptosis, a widespread phenomenon that occurs in the developmental stages of prokaryotic and eukaryotic cells, is controlled by specific genes, such as caspase-3, caspase-9, Bcl-2 and Bax (21,24,37-39). It also plays a pivotal role in biological evolution, embryonic development and dynamic homeostatic balance maintenance $(40,41)$. It was previously observed that NGR1 induced apoptosis in SW480 human colorectal cancer cells (17). In the present study, the results revealed that NGR1 induced apoptosis in cervical carcinoma cells. This conclusion was supported by the observed presence of apoptotic bodies that appeared in the nucleus, an increased rate of apoptosis, the upregulation of cleaved caspase- 3 and PARP1 protein expression levels, and the downregulation of Bcl-2 expression levels following NGR1 treatment.

Panax notoginseng extract, which includes notoginsenoside R1, ginsenosides Rg1, Re, Rb1, Rc and Rd, and isomeric ginsenosides $\mathrm{Rb} 2$ and $\mathrm{Rb} 3$, caused cell cycle arrest at $\mathrm{S}$ phase (16). The results of the current study also revealed that NGR1 arrested cells in the S phase, while simultaneously upregulating the expression levels of cyclin A2 and CDK2, and downregulating the expression levels of cyclin D1. DNA damage in cells is typically due to the biological environment or endogenous metabolic cell products (42). An intricate DNA repair system has since evolved to protect genomic stability, whereby ATR/ATM, p53 and PARP1 of the DDR signaling network are activated to participate in the repair of damaged DNA $(43,44), \gamma \mathrm{H} 2 \mathrm{AX}$, a marker of double-strand breaks (DSBs), is crucial in the cellular stress response to DNA damage and acts as a focal point for the recruitment of other protein assemblages to repair the DSBs (45-47). The present study also revealed that NGR1 induced H2AX phosphorylation in a dose- and time-dependent manner within the early experimental period $(<24 \mathrm{~h})$; however, with longer exposure, the expression of $\gamma \mathrm{H} 2 \mathrm{AX}$ decreased until it gradually returned to the normal levels (from 24 to $48 \mathrm{~h}$ ). These findings indicated that NGR1 may induce the DNA damage in the early stage, but the DNA double strands were completely degraded as the duration of NGR1 treatment increased. In addition, NGR1 upregulated p53 expression levels and the phosphorylation of ATR in a dose- and time-dependent manner, but downregulated the expression levels of PHF6 in a dose- and time-dependent manner. These results indicated that the downregulation of PHF6 expression may be negatively associated with DNA damage. 
Mutations in PHF6 were first discovered in BorjesonForssman-Lehmann syndrome, which is a rare $\mathrm{X}$-linked intellectual disability syndrome (48). Previous studies have revealed that PHF6 may be crucial for nucleolar transcriptional regulation and/or chromatin remodeling $(26,49)$ The knockdown of PHF6 was discovered to trigger a series of biochemical signaling pathways to participate in the repair of damaged ribosomal DNA in the nucleus, thus delaying the progression of the cell cycle and inhibiting the proliferation of cells $(25,27)$. In the present study, PHF6 was also discovered to be localized in the nucleoli. Hence, the relationship between PHF6 and $\gamma \mathrm{H} 2 \mathrm{AX}$ expression levels was subsequently investigated. The results demonstrated that PHF6 knockdown upregulated $\gamma \mathrm{H} 2 \mathrm{AX}$, but PHF6 overexpression downregulated $\gamma \mathrm{H} 2 \mathrm{AX}$, suggesting that PHF6 expression levels were negatively associated with $\gamma \mathrm{H} 2 \mathrm{AX}$ expression levels. In addition, compared with the control group, the expression levels of $\gamma \mathrm{H} 2 \mathrm{AX}$ were significantly increased in the PHF6 + NGR1 and siPHF6 + NGR1 groups; in particular, $\gamma \mathrm{H} 2 \mathrm{AX}$ was more abundant in the siPHF6 + NGR1 group. These findings indicated that the downregulation of PHF6 may enhance NGR1-mediated induction of DNA damage. The same findings were obtained from the immunofluorescence assays, as the number of $\gamma \mathrm{H} 2 \mathrm{AX}$ foci was highest in the siPHF6 + NGR1 group. In addition, PHF6 knockdown enhanced NGR1-mediated inhibition of cervical carcinoma cell viability. Altogether, the current data indicated that NGR1 may induce DNA damage to inhibit cell viability by downregulating PHF6.

In conclusion, the findings of the present study revealed that NGR1 was able to effectively inhibit the viability of cervical carcinoma cells in a dose- and time-dependent manner, resulting in apoptosis, the arrest of cells in the $S$ phase, the upregulation of cyclin A2 and CDK2 expression levels, and downregulation of cyclin D1 expression levels. In addition, the data also indicated that NGR1 induced DNA damage by downregulating the nucleolus protein PHF6, which enhanced NGR1-induced DNA damage and inhibited cervical carcinoma cell viability. The DNA repair function can resist the anticancer effects of chemotherapy drugs, leading to drug resistances50,51). Therefore, these findings may provide a novel target and therapeutic strategy for cancer therapies. NGR1 may have the potential to be applied in clinical settings for the treatment of cervical carcinoma in the future.

\section{Acknowledgements}

Not applicable.

\section{Funding}

The present study was funded by grants from the Traditional Chinese Medicine Bureau of Guangdong Province (grant no. 20181223), The Key Laboratory for Innovative Research on Medical Laboratory Technology of Longhua District, Shenzhen (grant no. 20150925A0410015) and The Science and Technology Innovation Project of Longhua District, Shenzhen (grant no. 2017115).

\section{Availability of data and materials}

The datasets used and/or analyzed during the current study are available from the corresponding author on reasonable request.

\section{Authors' contributions}

PM conceived and designed the study. TC performed the molecular experiments and wrote the manuscript. WW, YX, LZ and FP performed some of the experiments and analyzed the data. LG and XJ provided some reagents and performed flow cytometry experiments. TC and PM interpreted the data and critically revised the manuscript and confirm the authenticity of all the raw data. All authors read and approved the final manuscript.

\section{Ethics approval and consent to participate}

Not applicable.

\section{Patient consent for publication}

Not applicable.

\section{Competing interests}

The authors declare that they have no competing interests.

\section{References}

1. Ferlay J, Ervik M, Lam F, Colombet M, Mery L, Pineros M, Znaor A, Soerjomataram I and Bray F: Global Cancer Observatory: Cancer Today. International Agency for Research on Cancer. Lyon, 2018.

2. Siegel RL, Miller KD and Jemal A: Cancer statistics, 2015. CA Cancer J Clin 65: 5-29, 2015.

3. Silver MI and Kobrin S: Exacerbating disparities? Cervical cancer screening and HPV vaccination. Prev Med 130: 105902. 2020.

4. Cervical cancer analysis reveals new mutations. Cancer Discov 7: 344, 2017.

5. Kailash U, Soundararajan CC, Lakshmy R, Arora R, Vivekanandhan S and Das BC: Telomerase activity as an adjunct to high-risk human papillomavirus types 16 and 18 and cytology screening in cervical cancer. Br J Cancer 95: 1250-1257, 2006.

6. Sharma A, Rajappa M, Saxena A and Sharma M: Telomerase activity as a tumor marker in Indian women with cervical intraepithelial neoplasia and cervical cancer. Mol Diagn Ther 11: 193-201, 2007.

7. Li C, Ma C, Zhang W and Wang J: The immune function differences and high-risk human papillomavirus infection in the progress of cervical cancer. Eur J Gynaecol Oncol 35: 557-561, 2014.

8. Lindström AK and Hellberg D: Immunohistochemical LRIG3 expression in cervical intraepithelial neoplasia and invasive squamous cell cervical cancer: Association with expression of tumor markers, hormones, high-risk HPV-infection, smoking and patient outcome. Eur J Histochem 58: 2227, 2014.

9. Falletta P, Sanchez-del-Campo L, Chauhan J,Effern M,Kenyon A, Kershaw CJ, Siddaway R, Lisle R, Freter R, Daniels MJ, et al: Translation reprogramming is an evolutionarily conserved driver of phenotypic plasticity and therapeutic resistance in melanoma. Genes Deve 31: 18-33, 2017.

10. Wang F, Li L, Liu B, Chen Z and Li C: Hyaluronic acid decorated pluronic P85 solid lipid nanoparticles as a potential carrier to overcome multidrug resistance in cervical and breast cancer. Biomed Pharmacother 86: 595-604, 2017.

11. Yang BR, Cheung KK, Zhou X, Xie RF, Cheng PP, Wu S, Zhou ZY, Tang JY, Hoi PM, Wang YH and Lee SM: Amelioration of acute myocardial infarction by saponins from flower buds of Panax notoginseng via pro-angiogenesis and anti-apoptosis. J Ethnopharmacol 181: 50-58, 2016.

12. Wang P, Zhang L, Yao J, Shi Y, Li P and Ding K: An arabinogalactan from flowers of Panax notoginseng inhibits angiogenesis by BMP2/Smad/Id1 signaling. Carbohydr Polym 121: 328-335, 2015. 
13. Su P, Wang L, Du SJ, Xin WF and Zhang WS: Advance in studies of Panax notoginseng saponins on pharmacological mechanism of nervous system disease. Zhongguo Zhong Yao Za Zhi 39: 4516-4521, 2014 (In Chinese).

14. Xia W, Sun C, Zhao Y and Wu L: Hypolipidemic and antioxidant activities of sanchi (Radix notoginseng) in rats fed with a high fat diet. Phytomedicine 18: 516-520, 2011.

15. Zhao Y, Sun X, Yu X, Gao R and Yin L: Saponins from Panax notoginseng leaves improve the symptoms of aplastic anemia and aberrant immunity in mice. Biomed Pharmacother 102: 959-965, 2018.

16. He NW, Zhao Y, Guo L, Shang J and Yang XB: Antioxidant, antiproliferative, and Pro-apoptotic activities of a Saponin extract derived from the roots of Panax notoginseng (Burk.) F.H. Chen. J Med Food 15: 350-359, 2012

17. Yan Z, Zhu ZL, Wang HQ, Li W, Mi YX and Liu CX Pharmacokinetics of panaxatrol disuccinate sodium, a novel anti-cancer drug from Panax notoginseng, in healthy volunteers and patients with advanced solid tumors. Acta Pharmacol Sin 31: $1515-1522,2010$

18. Wan CZ, Xie JT, Fishbein A, Aung HH, He H, Mehendale SR, He TC, Du W and Yuan CS: Antiproliferative effects of different plant parts of Panax notoginseng on SW480 human colorectal cancer cells. Phytother Res 23: 6-13, 2009.

19. Cong S, Xiang L, Yuan X, Bai D and Zhang X: Notoginsenoside R1 up-regulates microRNA-132 to protect human lung fibroblast MRC-5 cells from lipopolysaccharide-caused injury. Int Immunopharmacol 68: 137-144, 2019.

20. Ming P, Cai T, Li J, Ning Y, Xie S, Tao T and Tang F: A novel arylbenzofuran induces cervical cancer cell apoptosis and G1/S arrest through ERK-mediated Cdk2/cyclin-A signaling pathway. Oncotarget 7: 41843-41856, 2016.

21. Chen DL, Engle JT, Griffin EA, Miller JP, Chu W, Zhou D and Mach RH: Imaging Caspase-3 activation as a marker of apoptosis-targeted treatment response in cancer. Mol Imaging Biol 17: 384-393, 2014.

22. Wang Y, Luo W and Wang Y: PARP-1 and its associated nucleases in DNA damage response. DNA Repair (Amst) 81: 102651, 2019.

23. Caron MC, Sharma AK, O'Sullivan J, Myler LR, Ferreira MT, Rodrigue A, Coulombe Y, Ethier C, Gagné JP, Langelier MF, et al Poly(ADP-ribose) polymerase-1 antagonizes DNA resection at double-strand breaks. Nat Commun 10: 2954, 2019.

24. Siddiqui WA, Ahad A and Ahsan H: The mystery of BCL2 family: Bcl-2 proteins and apoptosis: An update. Arch Toxicol 89: 289-317, 2015.

25. Todd MA, Huh MS and Picketts DJ: The sub-nucleolar localization of PHF6 defines its role in rDNA transcription and early processing events. Eur J Human Genet 10: 1453-1459, 2016.

26. Todd MA and Picketts DJ: PHF6 interacts with the nucleosome remodeling and deacetylation (NuRD) complex. J Proteome Res 11: 4326-4337, 2012 .

27. Wang J, Leung JWC, Gong Z, Feng L, Shi X and Chen J: PHF6 regulates cell cycle progression by suppressing ribosomal RNA synthesis. J Biol Chem 288: 3174-3183, 2013.

28. Zhao J, Cui L, Sun J, Xie Z, Zhang L, Ding Z and Quan X: Notoginsenoside R1 alleviates oxidized low-density lipoprotein-induced apoptosis, inflammatory response, and oxidative stress in HUVECS through modulation of XIST/miR-221-3p/TRAF6 axis. Cell Signall 76: 109781, 2020.

29. Zhong L, Zhou XL, Liu YS, Wang YM, Ma F, Guo BL, Yan ZQ and Zhang QY: Estrogen receptor $\alpha$ mediates the effects of notoginsenoside R1 on endotoxin-induced inflammatory and apoptotic responses in H9c2 cardiomyocytes. Mol Med Rep 12: 119-126, 2015

30. He K, Yan L, Pan CS, Liu YY, Cui YC, Hu BH, Chang X, Li Q, Sun K, Mao XW, et al: ROCK-dependent ATP5D modulation contributes to the protection of notoginsenoside NR1 against ischemia-reperfusion-induced myocardial injury. Am J Physiol Heart Circ Physiol 307: H1764-H1776, 2014.

31. Yu Y, Sun G, Luo Y, Wang M, Chen R, Zhang J, Ai Q, Xing N and Sun X: Cardioprotective effects of Notoginsenoside R1 against ischemia/reperfusion injuries by regulating oxidative stress- and endoplasmic reticulum stress-related signaling pathways. Sci Rep 6: 21730, 2016.

32. Peng Y, Li SN, Pei X and Hao K: The multivariate regression statistics strategy to investigate content-effect correlation of multiple components in Traditional Chinese Medicine based on a partial least squares method. Molecules 23: 545, 2018.
33. Li Y, Li Z, Jia Y, Ding B and Yu J: In vitro Anti-hepatoma activities of Notoginsenoside R1 through downregulation of tumor promoter miR-21. Dig Dis Sci 65: 1364-1375, 2019.

34. Lee CY, Hsieh SL, Hsieh S, Tsai CC, Hsieh LC, Kuo YH and Wu CC: Inhibition of human colorectal cancer metastasis by notoginsenoside R1, an important compound from Panax notoginseng. Oncol Rep 37: 399-407, 2017.

35. Limsuwanchote S, Wungsintaweekul J, Yusakul G, Han JY, Sasaki-Tabata K, Tanaka H, Shoyama Y and Morimoto S: Preparation of a monoclonal antibody against Notoginsenoside R1, a distinctive saponin from Panax notoginseng, and its application to indirect competitive ELISA. Planta Medica 80: 337-342, 2014

36. Sun HX, Chen Y and Ye Y: Ginsenoside Re and notoginsenoside R1: Immunologic adjuvants with low haemolytic effect. Chem Biodivers 3: 718-726, 2006.

37. Dwyer DJ, Camacho DM, Kohanski MA, Callura JM and Collins JJ: Antibiotic-induced bacterial cell death exhibits physiological and biochemical hallmarks of apoptosis. Mol Cell 46: 561-572, 2012.

38. Li Y, Zhou M, Hu Q, Bai XC, Huang W, Scheres SH and Shi Y: Mechanistic insights into caspase-9 activation by the structure of the apoptosome holoenzyme. Proc Natl Acad Sci USA 114: $1542-1547,2017$.

39. Funk K, Czauderna C, Klesse R, Becker D, Hajduk J, Oelgeklaus A, Reichenbach F, Fimm-Todt F, Lauterwasser J, Galle PR, et al: BAX redistribution induces apoptosis resistance and selective stress sensitivity in human HCC. Cancers (Basel) 12: 1437, 2020

40. Kulkarni S, Micci MA, Leser J, Shin C, Tang SC, Fu YY, Liu L, $\mathrm{Li}$ Q, Saha M, Li C, et al: Adult enteric nervous system in health is maintained by a dynamic balance between neuronal apoptosis and neurogenesis. Proc Natl Acad Sci USA 114: E3709-E3718, 2017.

41. Marchi S Patergnani S, Missiroli S, Morciano G, Rimessi A, Wieckowski MR, Giorgi C and Pinton P: Mitochondrial and endoplasmic reticulum calcium homeostasis and cell death. Cell Calcium 69: 62-72, 2018.

42. Stadler J and Richly H: Regulation of DNA repair mechanisms: How the chromatin environment regulates the DNA damage response. Int J Mol Sci 18: 1715, 2017.

43. Matsuoka S, Ballif BA, Smogorzewska A, McDonald ER III, Hurov KE, Luo J, Bakalarski CE, Zhao Z, Solimini N, Lerenthal Y, et al: ATM and ATR substrate analysis reveals extensive protein networks responsive to DNA damage. Science 316: 1160-1166, 2007.

44. Zheng L, Dai H, Zhou M, Li X, Liu C, Guo Z, Wu X, Wu J, Wang C, Zhong J, et al: Polyploid cells rewire DNA damage response networks to overcome replication stress-induced barriers for tumour progression. Nat Commun 3: 815, 2012

45. Lowndes NF and Toh GW: DNA repair: The importance of phosphorylating histone H2AX. Curr Biol 15: R99-R102, 2005.

46. Jakob B, Splinter J, Conrad S, Voss KO, Zink D, Durante M, Löbrich M and Taucher-Scholz G: DNA double-strand breaks in heterochromatin elicit fast repair protein recruitment, histone H2AX phosphorylation and relocation to euchromatin. Nucleic Acids Res 39: 6489-6499, 2011

47. Müller B, Ellinwood NM, Lorenz B and Stieger K: Detection of DNA double strand breaks by $\gamma \mathrm{H} 2 \mathrm{AX}$ does not result in $53 \mathrm{bp} 1$ recruitment in mouse retinal tissues. Front Neurosci 12: 286 , 2018.

48. Zhang C, Mejia LA, Huang J, Valnegri P, Bennett EJ, Anckar J, Jahani-Asl A, Gallardo G, Ikeuchi Y, Yamada T, et al: The X-linked intellectual disability protein PHF6 associates with the PAF1 complex and regulates neuronal migration in the mammalian brain. Neuron 78: 986-993, 2013.

49. Vallée D, Chevrier E, Graham GE, Lazzaro MA, Lavigne PA, Hunter AG and Picketts DJ: A novel PHF6 mutation results in enhanced exon skipping and mild Borjeson-Forssman-Lehmann syndrome. J Med Genet 41: 778-783, 2004.

50. Rocha CRR, Silva MM, Quinet A, Cabral-Neto JB and Menck CFM: DNA repair pathways and cisplatin resistance: An intimate relationship. Clinics (Sao Paulo) 73 (Suppl 1): e478s, 2018.

51. Salehan MR and Morse HR: DNA damage repair and tolerance: A role in chemotherapeutic drug resistance. Br J Biomed Sci 70: 31-40, 2016.

This work is licensed under a Creative Commons

Attribution-NonCommercial-NoDerivatives 4.0 International (CC BY-NC-ND 4.0) License. 